
January 1935

\title{
A MAXWELL TRIANGLE YIELDING UNIFORM CHROMATICITY SCALES
}

\author{
By Deane B. Judd
}

\begin{abstract}
A colorimetric coordinate system has been found by trial and error whose Maxwell triangle has the useful property that the length of any line on it is a close measure of the chromaticity difference between the stimuli represented at the extremes of the line. Such accurate chromaticity scales may be derived from this triangle merely by stepping off equal intervals on it that it has been called the "uniform-scale triangle." The definition of the system is given, and also a comparison of experimental sensibility data with corresponding data derived from the triangle. An important application of this coordinate system is its use in finding from any series of colors the one most resembling a neighboring color of the same brilliance, for example, the finding of the nearest color temperature for a neighboring non-Planckian stimulus. The method is to draw the shortest line from the point representing the non-Planckian stimulus to the Planckian locus.
\end{abstract}

\section{CONTENTS}

I. Introduction

II. Mathematical analysis _._.

III. Mixture diagram _..._. 43

IV. Comparison with experimental data $\ldots \ldots \ldots \ldots \ldots \ldots \ldots$

1. Sensibility to change in dominant wave length at constant purity

(a) Sensibility at unit purity

(b) Ratio of sensibility at purity, $p$, to that at unit purity ${ }_{--} \quad 46$

2. Sensibility to change in purity, dominant wave-length constant_ 47

(a) Sensibility as a function of purity ........... 47

(b) Sensibility near zero purity $\ldots$

(c) Number of steps between zero and unit purity as a function of wave length

3. Sensibility to change in color temperature

4. Sensibility to change in Lovibond number

(a) Sensibility to change in Lovibond yellow ........ 53

(b) Sensibility to change in Lovibond red combined with 35 yellow

5. Conclusions from the comparisons

V. Applications of the triangle

VI. Summary

VII. Appendix 


\section{INTRODUCTION}

In a previous paper ${ }^{1}$ experimental data on chromaticity sensibility were related to the $(r, g)$-plot of the OSA tristimulus coordinate system. The method of relation was called the "square construction" because by that method the locus of points representing chromatic colors equally distinguishable from any one given color of the same brilliance is a square centered on the point representing the given color.

The present method of relating chromaticity sensibility to the Maxwell triangle is the graphically more convenient "circle construction." When applied to the OSA colorimetric coordinate system, the circle construction resulted in poorer agreement with sensibility data than the analytically simple square construction. A new coordinate system has been derived, however, for the sole purpose of making use of the circle construction to the best advantage on the equilateral Maxwell triangle. This paper gives the definition of the new tristimulus coordinate system, shows the degree of agreement obtained with both the data previously assembled and those which have become available since, and points out the uses to which the Maxwell triangle of this coordinate system may be put.

\section{MATHEMATICAL ANALYSIS}

If any two color stimuli specified by points $\left(r_{1}, g_{1}, b_{1}\right)$ and $\left(r_{2}, g_{2}, b_{2}\right)$ on the equilateral tringle are compared, with brightnesses equalized, the circle construction states that the chromaticity difference, $\Delta E$, between them is proportional to the distance, $D$, between the points representing them, or:

$$
K \Delta E=D
$$

where $K$ is a constant of proportionality dependent on the unit (least perceptible difference, probable error and so on) in which $\Delta E$ is expressed and on the experimental conditions such as field size and field brightness. ${ }^{2}$

From the geometry of the equilateral triangle the distance, $D$, may be expressed in terms of the differences between the trilinear coordinates, writing $\Delta r, \Delta g, \Delta b$ as abbreviations for $r_{1}-r_{2}, g_{1}-g_{2}, b_{1}-b_{2}$, respectively, thus:

$$
D=\sqrt{2\left[(\Delta r)^{2}+(\Delta g)^{2}+(\Delta b)^{2}\right] / 3}
$$

where unit $D$ is the altitude of the triangle. This relation may also be written in a form particularly convenient for dealing with a number of distances in the same direction. Let $\Delta v$ be any one of $\Delta r$, $\Delta g, \Delta b$, and $\Delta q$ be either of the remaining two, then:

$$
D=\frac{2 \Delta v}{\sqrt{3}} \sqrt{(\Delta q / \Delta v)^{2}+(\Delta q / \Delta v)+1}
$$

$(\Delta q / \Delta v)$ constant being the condition for distances in the same direction on the triangle.

1 D. B. Judd ,Chromaticity sensibility to stimulus differences, J. Opt. Soc. Am. 22, 72 (1932).

2 J.Opt . Soc. Am. 22, 87 (1932). 
In a few cases where the circle construction is analytically inconvenient, the nearly equivalent hexagon construction has been substituted. According to this construction:

$$
\begin{aligned}
K \Delta E & =\Delta c \\
& =|\Delta r|,|\Delta g|, \text { or }|\Delta b|, \text { whichever is the largest; }\} \\
& =(|\Delta r|+|\Delta g|+|\Delta b|) / 2
\end{aligned}
$$

where the absolute value signs $(||)$ indicate that the differences are to be taken all greater than zero. The hexagon construction differs from the circle construction by a factor varying from $2 / \sqrt{3}$ to 1 , or by a maximum of about 15 percent. It may be substituted for the circle construction if differences of this size are not significant.

\section{MIXTURE DIAGRAM}

The coordinate system found by trial and error to yield the best agreement with chromaticity sensibility may conveniently be defined as a projective transformation of the 1931 ICI standard coordinate system for colorimetry. ${ }^{3}$ If $\bar{x}, \bar{y}, \bar{z}$ be the tristimulus specifications of a given color stimulus on the ICI system, then $\bar{r}, \bar{g}, \bar{b}$, the tristimulus specifications on the uniform-scale system, may be found as:

$$
\begin{aligned}
& \bar{r}=3.1956 \bar{x}+2.4478 \overline{\bar{y}}-0.1434 \bar{z} \\
& \bar{g}=-2.5455 \bar{x}+7.0492 \bar{y}+0.9963 \frac{\bar{z}}{\bar{z}} \\
& \bar{b}=0.0000 \mathrm{x}+0.0000 \frac{\bar{y}}{\mathrm{~b}}+1.0000 \frac{\mathrm{z}}{}
\end{aligned}
$$

The reverse transformation is given by:

$$
\left.\begin{array}{l}
\bar{x}=0.24513 \frac{\bar{r}}{\bar{x}}=0.08512 \bar{g}+0.11996 \bar{b} \\
\bar{y}=0.08852 \bar{r}+0.11112 \bar{g}-0.09802 \bar{b} \\
\bar{z}=0.00000 \bar{r}+0.00000 \bar{g}+1.00000 \bar{b}
\end{array}\right\}
$$

For convenience in checking arithmetical results the coefficients of these transformation equations are given to at least three more decimal places than would be significant from the trial-and-error adjustment to experimentally known chromaticity sensibility.

It may be noted that the only way in which better agreement with sensibility data may be effected is by a transformation which alters the shape of the spectrum locus. Transformations which merely displace the locus with respect to the triangle, or reorient it, or expand or contract it uniformly do not at all change the agreement. The system defined by eq 3 is one of many possible systems giving this particular shape to the spectrum locus. The luminosity coefficients are $L_{r}=0.08852, L_{0}=0.11112, L_{b}=-0.09802$.

The uniform-scale system is more closely allied to the OSA coordinate system ${ }^{4}$ by derivation than to the ICI system. The coefficients of transformation between the uniform-scale system and the OSA system are:

$$
\left.\begin{array}{c}
\text { OSA to uniform-scale } \\
1,0,0.1 \\
0,1,0.1 \\
0,0,0.2 \\
\text { Uniform-scale to OSA } \\
1,0,-0.5 \\
0,1,-0.5 \\
0,0,5.0
\end{array}\right\}
$$

\footnotetext{
${ }^{3}$ Proc. 8th session, International Commission on Illumination, Cambridge, pages 19 to 29 (September 1931). D. B. Judd, The 1931 ICI standard observer and coordinate system for colorimetry, J. Opt. Soc. Am. 23, 359 (1933). T. Smith and J. Guild, The CIE colorimetric standards and their use, Trans. Opt. Soc. 33, 73 (1931-32).

4 J. Opt. Soc. Am. 22, 102 (1932).
} 
These coefficients have been used in transforming data on the OSA basis referring to Lovibond glasses, but in the other comparisons presented, the 1931 ICI standard observer and eq 3 have been used.

Figure 1 shows the spectrum locus and the Planckian locus on the equilateral Maxwell triangle of the new uniform-scale system. A given color stimulus $(\bar{r}, \bar{g}, \bar{b})$ is represented on this triangle according to its trilinear coordinates $(r, g, b)$ which are fractional parts of the total, $\bar{r}+\bar{g}+\bar{b}$, and refer to distances perpendicular to a side of the triangle. Table 1 gives the trilinear coordinates from which the spectrum locus and the Planckian locus on figure 1 have been plotted; it also gives the trilinear coordinates of the recombined equal-energy spectrum which is the basic stimulus of the ICI system, Abbot-Priest sunlight, ${ }^{5}$ mean noon sunlight from Abbot's data as averaged by Davis and Gibson, ${ }^{6}$ and sunlight outside the atmosphere from Abbot's data. $^{7}$

TABI.E 1.-Trilinear coordinates on the uniform-chromaticity-scale triangle

Observer: 1931 ICI standard

PART 1, FOR THE SPECTRUM

\begin{tabular}{|c|c|c|c|c|c|c|c|}
\hline $\begin{array}{l}\text { Wave } \\
\text { length }\end{array}$ & $r$ & $g$ & $b$ & $\begin{array}{l}\text { Wave } \\
\text { length }\end{array}$ & $r$ & $g$ & $b$ \\
\hline $\mathrm{m}_{380}$ & .2681 & 0.2437 & 0.4881 & $\mathrm{~m}_{550}^{\mu}$ & 0.3918 & 0.6072 & 0.0009 \\
\hline 410 & .2648 & .2461 & .4891 & 570 & $\begin{array}{l}.4404 \\
.4995\end{array}$ & $\begin{array}{l}.0582 \\
.5003\end{array}$ & $\begin{array}{l}.0004 \\
.0002\end{array}$ \\
\hline $\begin{array}{l}430 \\
440\end{array}$ & $\begin{array}{l}.2575 \\
.2495\end{array}$ & $\begin{array}{r}.2584 \\
.2761\end{array}$ & $\begin{array}{r}4841 \\
.4744\end{array}$ & $\begin{array}{l}580 \\
590\end{array}$ & $\begin{array}{l}.508 \\
.6532\end{array}$ & $\begin{array}{l}.4291 \\
.3467\end{array}$ & .0001 \\
\hline $\begin{array}{l}450 \\
460 \\
470 \\
480 \\
490\end{array}$ & $\begin{array}{l}.2363 \\
.2173 \\
.1961 \\
.1833 \\
.1906\end{array}$ & $\begin{array}{r}.3049 \\
.3493 \\
.4226 \\
.5353 \\
.6467\end{array}$ & $\begin{array}{l}.4588 \\
.4334 \\
.3813 \\
.2814 \\
.1627\end{array}$ & $\begin{array}{l}600 \\
610 \\
620 \\
630 \\
640\end{array}$ & $\begin{array}{l}.7388 \\
.8169 \\
.8776 \\
.9206 \\
.9521\end{array}$ & $\begin{array}{l}.2611 \\
.1830 \\
.1224 \\
.0793 \\
.0478\end{array}$ & $\begin{array}{l}.0001 \\
.0001 \\
.0001 \\
.0000 \\
.0000\end{array}$ \\
\hline $\begin{array}{l}500 \\
510 \\
520 \\
530 \\
540\end{array}$ & $\begin{array}{l}.2147 \\
.2440 \\
.2784 \\
.3145 \\
.3511\end{array}$ & $\begin{array}{l}.7092 \\
.7249 \\
.7103 \\
.6805 \\
.6467\end{array}$ & $\begin{array}{l}.0761 \\
.0312 \\
.0113 \\
.0050 \\
.0022\end{array}$ & $\begin{array}{l}650 \\
700\end{array}$ & $\begin{array}{r}.9728 \\
1.0000\end{array}$ & $\begin{array}{l}.0272 \\
.0000\end{array}$ & $\begin{array}{l}.0000 \\
.0000\end{array}$ \\
\hline
\end{tabular}

PART 2, FOR THE PLANCKIAN RADIATOR

\begin{tabular}{|c|c|c|c||c|c|c|c|}
\hline $\begin{array}{c}\text { Color } \\
\text { temper- } \\
\text { ature }\end{array}$ & $r$ & $g$ & $b$ & $\begin{array}{c}\text { Color } \\
\text { temper- } \\
\text { ature }\end{array}$ & $r$ & $g$ & $b$ \\
\cline { 1 - 5 } $\mathrm{K}$ & & & & $\circ \mathrm{K}$ & & & \\
100 & 1.0000 & 0.0000 & 0.0000 & 2,848 & 0.5434 & 0.4239 & 0.0327 \\
300 & .9981 & .0019 & .0000 & 3,500 & .5103 & .4427 & .0470 \\
600 & .9237 & .0763 & .0000 & 4,800 & .4696 & .4598 & .0706 \\
1,000 & .7906 & .2086 & .0008 & 6,500 & .4409 & .4672 & .0920 \\
1,500 & .6809 & .3140 & .0051 & 10,000 & .4142 & .4699 & .1159 \\
1,900 & .6242 & .3640 & .0118 & 24,000 & .3898 & .4685 & .1417 \\
2,360 & .5783 & .4001 & .0216 & $\infty$ & .3769 & .4663 & .1568 \\
\hline
\end{tabular}

PART 3, FOR SOME MISCELLANEOUS STIMULI

\begin{tabular}{c|r|r}
$r$ & \multicolumn{1}{c|}{$g$} & \multicolumn{1}{c}{$b$} \\
\cline { 3 - 3 } 0.4607 & 0.4665 & \\
.4572 & .4688 & .0728 \\
.4402 & .4713 & .0740 \\
.4583 & .4583 & .0885 \\
& & .0833 \\
\hline
\end{tabular}

s I. G. Priest, A precision method for producing artificial daylight. Phys. Rev. [2], 11, 502 (1918); J. Opt. Soc. Am. and Rev. Sci. Inst., 12, 479 (1926). D. B. Judd, Reduction of data on mixture of color stimuli. BS J. Research, 4, 525 (1930) RP163.

${ }_{6} \mathrm{R}$. Davis and K. S. Gibson, Filters for the reproduction of sunlight and daylight and the determination of color temperature. Misc. Pub. BS 114, 16 (1931).

${ }^{7}$ See table 1 in article cited in footnote 6 . 


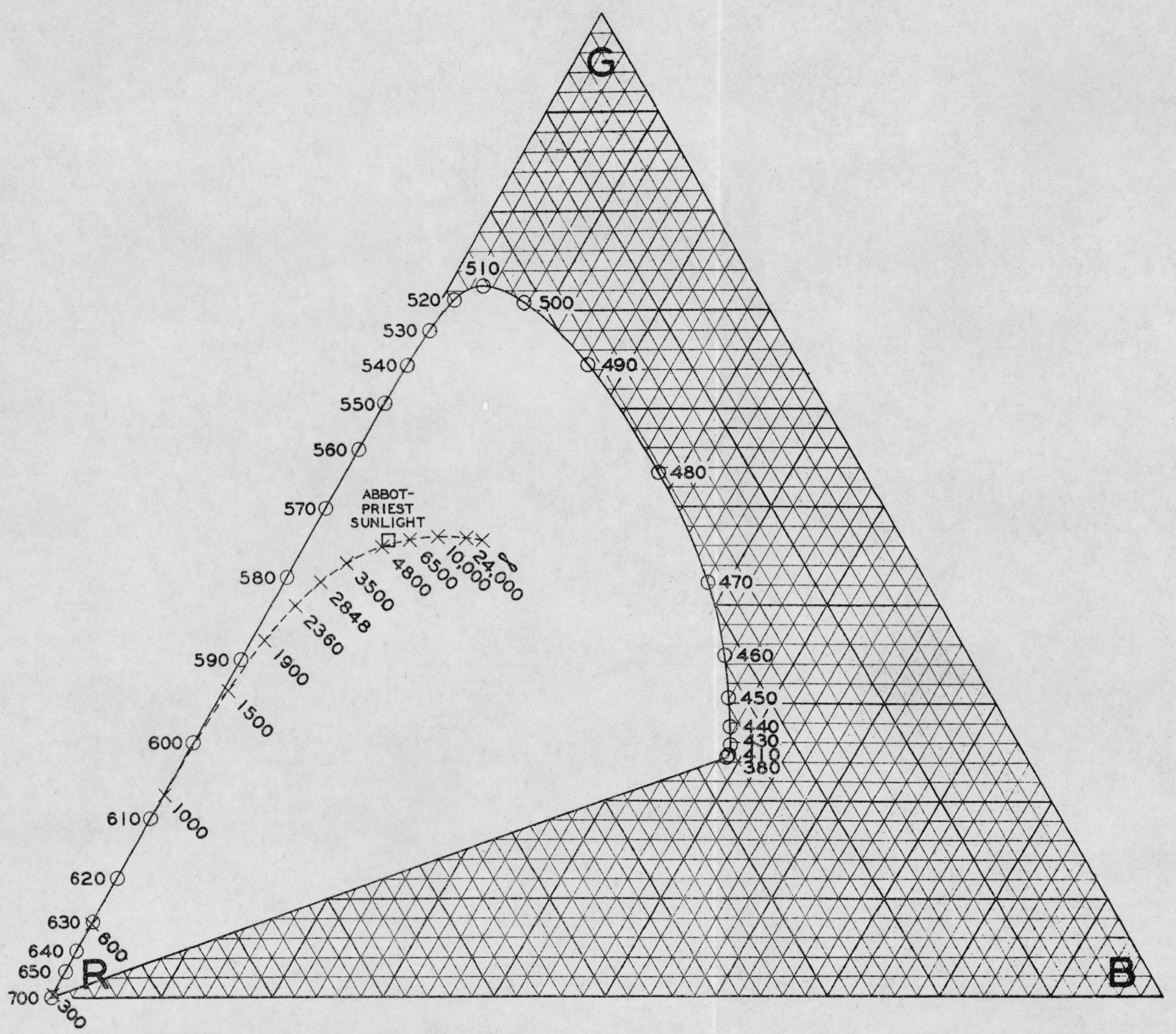

FIGURE 1.--The uniform-chromaticity-scale triangle.

Wave length along the spectrum locus is indicated in millimicrons; color temperature along the Planckian locus is given in degrees Kelvin. 
On this triangle equal chromaticity intervals are represented by lines of nearly equal length. An outstanding difference between this and the usual Maxwell triangle is the smaller distance between the Planckian locus and the spectrum locus from 550 to $600 \mathrm{~m} \mu$.

\section{COMPARISON WITH EXPERIMENTAL DATA}

As in the previous paper the method of comparison is to plot the various types of chromaticity-sensibility data on the same graph with similar data derived from the triangle by equation 1 or 1 a. The constant, $K$, is adjusted to a value providing nearly the best agreement in order to facilitate comparison.

In the derivation of the new coordinate system, considerably more weight was given to some chromaticity-sensibility data than to others. These weights were determined in no very systematic or quantitative way; they depended on a critical survey of the whole body of data and on estimates of relative reliability of the various sets of data. Of the rather large proportion of the data not taken into account in the actual derivation of the system, much was found to be in good agreement. All the data yielding sufficiently good agreement to warrant graphical comparison are shown, however, without regard to the weight given them in deriving the system. Data which do not agree well are not shown but are mentioned at appropriate places in the text.

\section{SENSIBILITY TO CHANGE IN DOMINANT WAVE LENGTH AT CONSTANT PURITY}

(a) SENSIBILITY AT UNIT PURITY

By equation 1a the hexagon construction yields for this case:

$$
d \lambda / d E=K /\left(d c_{h} / d \lambda\right)_{p=1}
$$

where $\lambda$ is wave length and $\left(d c_{h} / d \lambda\right)_{p=1}$ is the largest of $|d r / d \lambda|$, $|d g / d \lambda|,|d b / d \lambda|$ referring to the spectrum locus. Figure 2 compares experimental values of $d \lambda / d E$ with $0.007 /\left(d c_{h} / d \lambda\right)_{p=1}$ which is shown by the solid line. The experimental data indicated by points are those given in figure 3 of the previous paper ${ }^{8}$ to these has been added a dotted curve representing the result of a recent careful investigation with modern apparatus by Wright and Pitt. ${ }^{9}$

The degree of agreement shown by figure 2 is good but not perfect. The solid curve rises somewhat too high near $510 \mathrm{~m} \mu$ and stays too low near 470 . The curves of results by Laurens and Hamilton ${ }^{10}$ showing pronounced seccondary minima not duplicated in the solid curve have not been given; a discussion of the reliability of these omitted results is given by Wright and Pitt. ${ }^{11}$

\footnotetext{
8 J. Opt. Soc. Am. 22, 89 (1932).

${ }^{\circ}$ W. D. Wright and F. H. G. Pitt, Hue-discrimination in normal colour-vision. Proc. Phys. Soc. 46, 459 (1934).

${ }_{10}$ H. Laurens and W. F. Hamilton, The sensibility of the eye to differences in wave length. Am. J. Physiol, 65, 547 (1923).

11 Proc. Phys. Soc. 46, 466 (1934).
} 


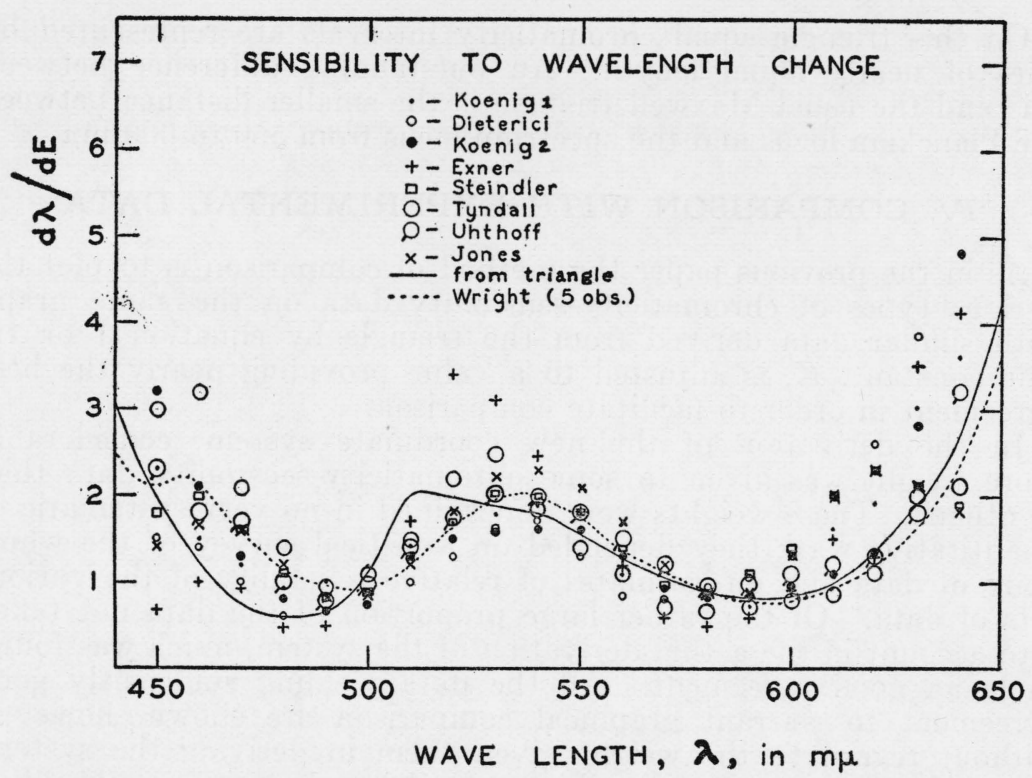

FIGURE 2.-Chromaticity sensibility to wave-length change in the spectrum.

(b) RATIO OF SENSIBILITY AT PURITY, $p$, TO THAT AT UNIT PURITY

Analogous to equation $9 \mathrm{a}$ of the previous paper extended to the general choice of heterogeneous stimulus ${ }^{12}$ the hexagon construction yields:

$$
\frac{(d \Lambda / d E)_{p}}{(d \lambda / d E)_{p=1}}=\frac{\left[s_{h}(1-p)+s_{w} p\right]^{2}\left(d c_{h} / d \lambda\right)}{s_{w} p\left\{\left[s_{h}(1-p)+s_{w} p\right]\left(d c_{h} / d \lambda\right)+(1-p)\left(c_{w}-c_{h}\right)\left(d s_{h} / d \lambda\right)\right\}}
$$

where $\Lambda$ is dominant wave length, $s_{h}$ is an abbreviation for $r L_{r}+g L_{g}+$ $b L_{b}$ for the spectrum at wave length, $\Lambda, s_{w}$ is an abbreviation for the similar sum referring to the heterogeneous stimulus ("white light"), and $c$ as in equation 1a is either $r, g$, or $b$. As discussed in the previous paper, care must be taken in applying this formula because of the multiple definition of $c_{h}$. In the numerator, $c_{h}$ is taken as $r, g$, or $b$ according as $d r / d \lambda, d g / d \lambda$, or $d b / d \lambda$ has the greatest absolute value for the spectrum $(p=1)$. In the denominator, $c_{h}$ is chosen as $r, g$, or $b$ according to which choice makes the absolute value of the denominator the greatest. For most values of wave length, $c_{h}$ is the same in the numerator and denominator, but not at all wave lengths.

In figure 3 are shown the experimental values of this ratio obtained by Tyndall ${ }^{13}$ (circles) and those obtained by Watson ${ }^{14}$ (crosses). The data by Watson shown on plots marked 530, 585, and 630 refer to wave lengths 527,589 , and $632 \mathrm{~m} \mu$, respectively. The curves shown were obtained from equation 5 with Abbot-Priest sunlight as the heterogeneous stimulus, that is, for $r_{w}=0.461, g_{w}=0.466, b_{w}=0.073$.

${ }_{12}$ D. B. Judd, A general formula for the computation of colorimetric purity. BS J. Research 7, 827 (1931) RP377; see equation 14 .

${ }_{13}$ E. P. T. Tyndall, Chromaticity sensibility to wave-length difference as a function of purity. J. Opt. Soc. Am. 23, 15 (1933).

${ }_{14}$ W. Watson, Note on the sensibility of the eye to variations of wave length. Proc. Roy. Soc. B. 84, 118 (1911). 
This choice was made because the heterogeneous stimulus used by Tyndall was a color match for Abbot-Priest sunlight; that used by Watson was similar but not definitely known.

It will be noted from figure 3 that the agreement at three dominant wave lengths $(455,490$, and $630 \mathrm{~m} \mu)$ is nearly perfect. In the other three cases the experimentally found relation is similar to that yielded by the triangle but not identical.

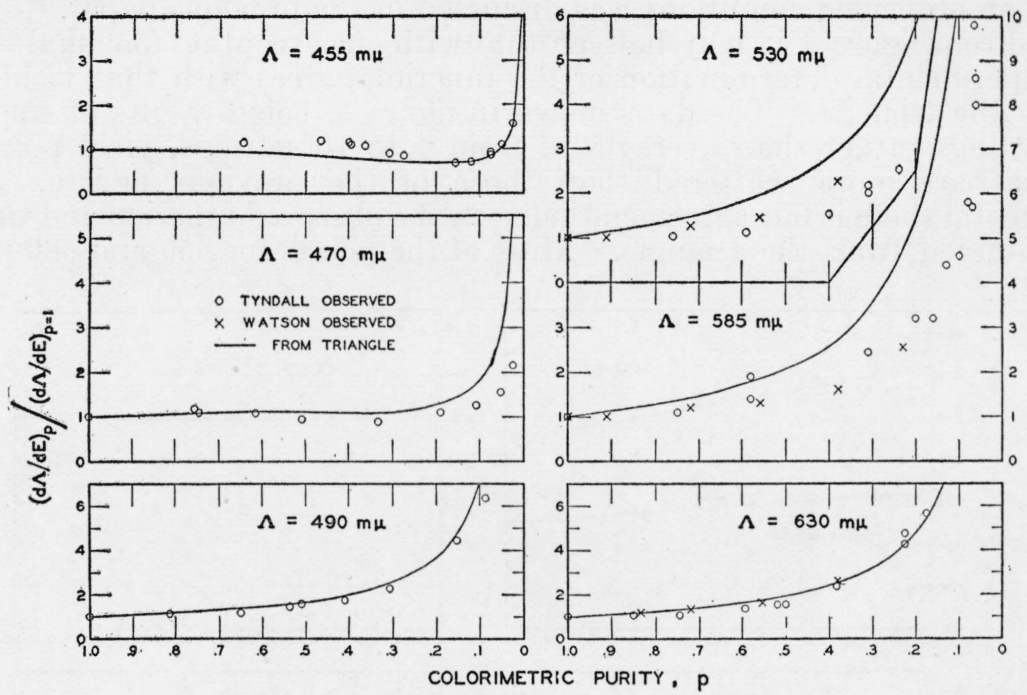

FIGURE 3.-Chromaticity sensibility to dominant-wave-length change as a function of purity.

\section{SENSIBILITY TO CHANGE IN PURITY, DOMINANT WAVE- LENGTH CONSTANT}

\section{(a) SENSIBILITY AS A FUNCTION OF PURITY}

Analogous to equation 10a of the previous paper extended as was equation 5 to the general choice of heterogeneous stimulus it is seen from equations 1 and $2 \mathrm{a}$ that the circle construction yields:

$$
\left(\frac{d p}{d E}\right)_{\Delta \text { constant }}=\frac{K}{2} \sqrt{\frac{3}{(\Delta q / \Delta v)^{2}+(\Delta q / \Delta v)+1}} \frac{\left[s_{h}(1-p)+s_{w} p\right]^{2}}{s_{h} s_{w}\left(v_{h}-v_{w}\right)}
$$

where, as in equation 2a, $v$ is any one of $r, g, b$, and $q$ is either of the remaining two; $\Delta v$ may be evaluated conveniently here as $v_{h}-v_{w}$, $v_{h}$ referring to the spectrum at wave length, $\Lambda$, and $v_{w}$ to the heterogeneous stimulus; $\Delta q$ similarly may be found as $q_{n}-q_{w}$.

In figure 4 are shown a number of experimental determinations of this quantity by Donath ${ }^{15}$ (circles) and a determination by Judd ${ }^{16}$ (crosses). In figure 5 are shown all of the published experimental data on this case in the recent paper by Martin, Warburton, and Morgan. ${ }^{17}$ The curves in figures 4 and 5 refer to wave lengths

15 F. Donath, Die funktionale Abhängigkeit zwischen Reiz und Empfindung bei der Farbensättigung. Neue Psych. Stud. 2, 143 (1926).

16 J. Opt. Soc. Am. 22,94 (1932).

17 L. C. Martin, F. L. Warburton, and W. J. Morgan, Determination of the Sensitiveness of the Eye to Differences in the Saturation of Colours, Medical Research Council, Reports of the Committee upon the Physiology of Vision, XIII, Special Report Series, no. 188, London (1933).

$100452-35-4$ 
approximately but not identically those of the experimental results and were obtained from equation 6 , those in figure 4 with $K$ adjusted in each case, those in figure 5 with $K$ adjusted to 0.015 throughout. Values of $K$ referring to Donath's work which was done with an improved technic involving rotating disks viewed by both eyes vary from 0.0014 to 0.0023 ; the value of $K$ for Judd's result referring to a $2^{\circ}$ field viewed with one eye is 0.011 . The marked dependence of $K$ on observing conditions was discussed in the previous paper.

From figure 4 it may be seen that with one exception $(550 \mathrm{~m} \mu)$ the experimental determination of the function agrees with that yielded by the triangle. The data shown in figure 5 , being results of single settings rather than averages of from 4 to 10 settings, yield points that are more scattered than those of the previous figures. In general there is fair agreement between the observed function and that obtained from the triangle. Most of the points for 650 and $680 \mathrm{~m} \mu$
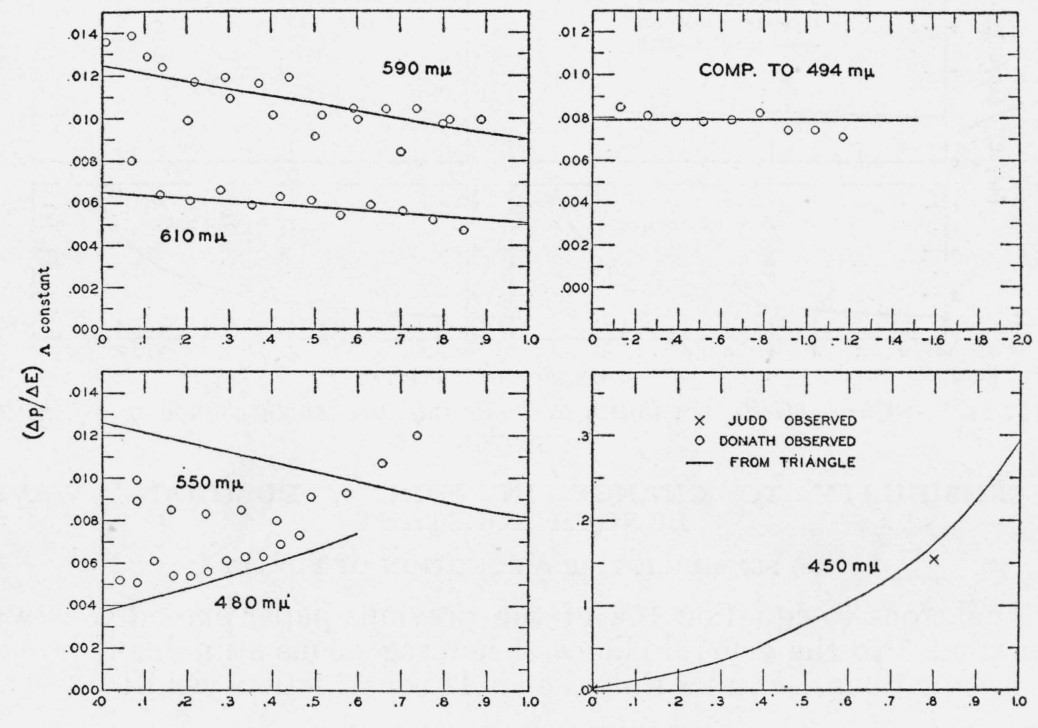

FiguRe 4.-Chromaticity sensibility to purity change as a function of purity.

are higher than the curve; perhaps some of the discrepancy at these wave lengths is ascribable to a low field brightness for this extreme spectral region. There is a general tendency throughout for the experimental data to indicate a rise in $d p / d E$ with purity for low purities. Some of this rise has been ascribed by the authors to a fatigue effect combined with the fact that the majority of the stepby-step settings progressed upward from zero purity; the settings in which the progression was in the opposite direction substantiate this view. It is probably significant that of all wave lengths investigated, that $(460 \mathrm{~m} \mu)$ yielding the most consistent rise for low purities is the only one for which the triangle also indicates a rise. Note also that the observed function for $546 \mathrm{~m} \mu$ in figure 5 is convex upward while that in figure 4 for $550 \mathrm{~m} \mu$ is convex downward, the average being in fair agreement with the function computed from the triangle. 
Data by Nutting and Jones, ${ }^{18}$ and Jones and Lowry ${ }^{19}$ deviate considerably from each other and from the functions yielded by the triangle; they are not shown graphically. Possible sources of error in these sets of data have already been discussed. ${ }^{20}$
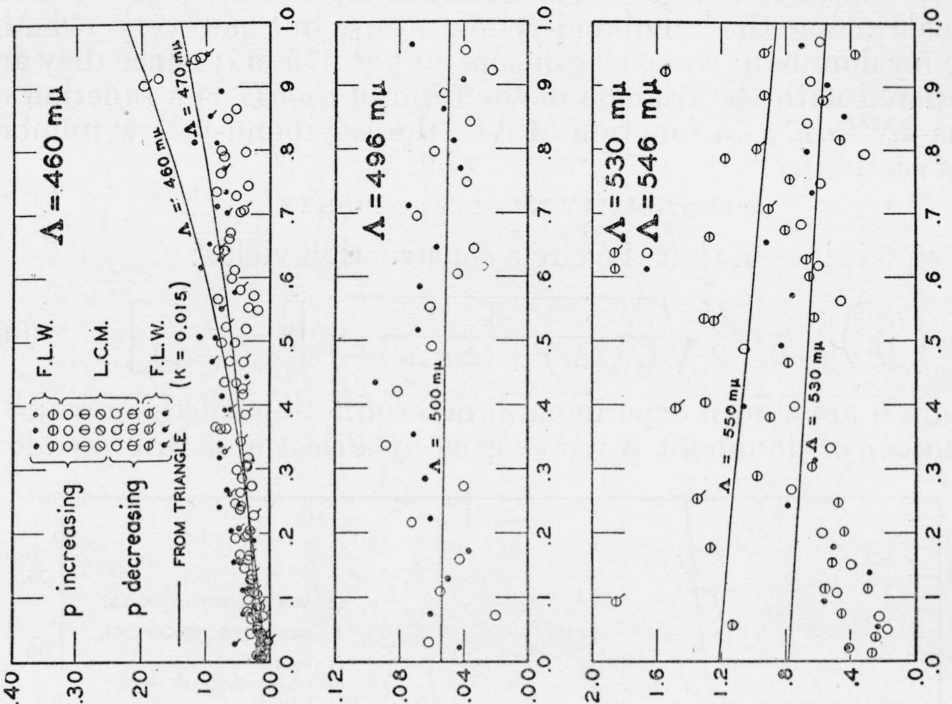

-
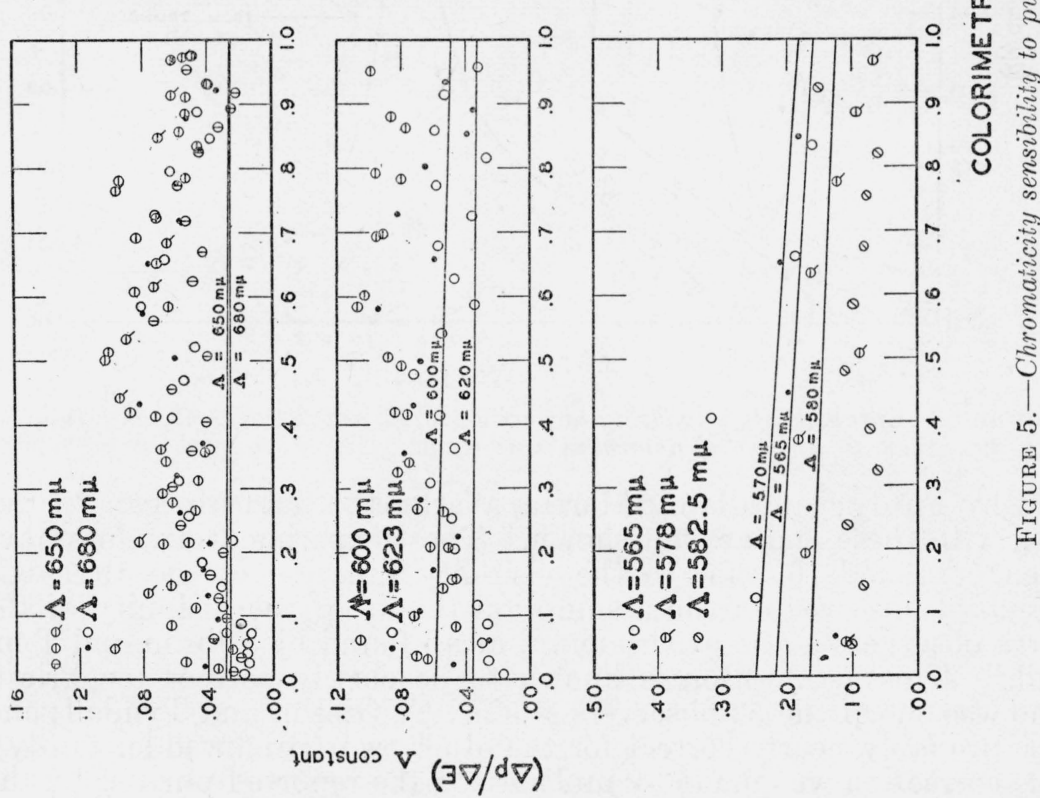

Data by Judd ${ }^{21}$ obtained through a different means (Lovibond yellow glasses) than other sets cited here deviate from the function

${ }_{18}^{18}$ P. G. Nutting, The retinal sensibilities related to illuminating engineering. Trans. Illum. Eng. Soc. 11, 16 (1916)

19 L. A. Jones, and E. M. Lowry, Retinal sensibility to saturation differences. J. Opt. Soc. Am. and Rev. Sci. Inst., 13, 25 (1926).

20 J Opt. Soc Am. 22, 95 (1932); see also footnote 17, p. 47.

${ }_{21}$ D. B. Judd, Saturation scale for yellow colors J. Opt. Soc. Am. 23, 35 (1933). 
indicated by the triangle by a factor of about 2.5. Reexamination of these data has shown that an appreciable part of the deviation can be ascribed to the two-millimicron dominant-wave-length variation from one end of the Lovibond-yellow locus to the other which was previously considered negligible. These data, therefore, give a saturation scale along the Lovibond-yellow locus, but not very exactly the scale for dominant wave length constant at $575 \mathrm{~m} \mu$; hence they are not compared with the triangle in the form of $d p / d E$ as a function of $p$, but as $d N^{\prime \prime} / d E$ as a function of $N^{\prime \prime}$, the Lovibond-yellow number (see later section).

(b) SENSIBILITY NEAR ZERO PURITY

From eq 6 it is seen that the circle construction yields:

$$
\left(\frac{d p}{d E}\right)_{p \rightarrow 0}=\frac{K}{2} \sqrt{\frac{3}{(\Delta q / \Delta v)^{2}+(\Delta q / \Delta v)+1}}\left[\frac{s_{h}}{s_{w}\left(v_{h}-v_{w}\right)}\right]
$$

In figure 6 are shown experimental determinations of this quantity for a number of dominant wave lengths by Priest and Brickwedde ${ }^{22}$

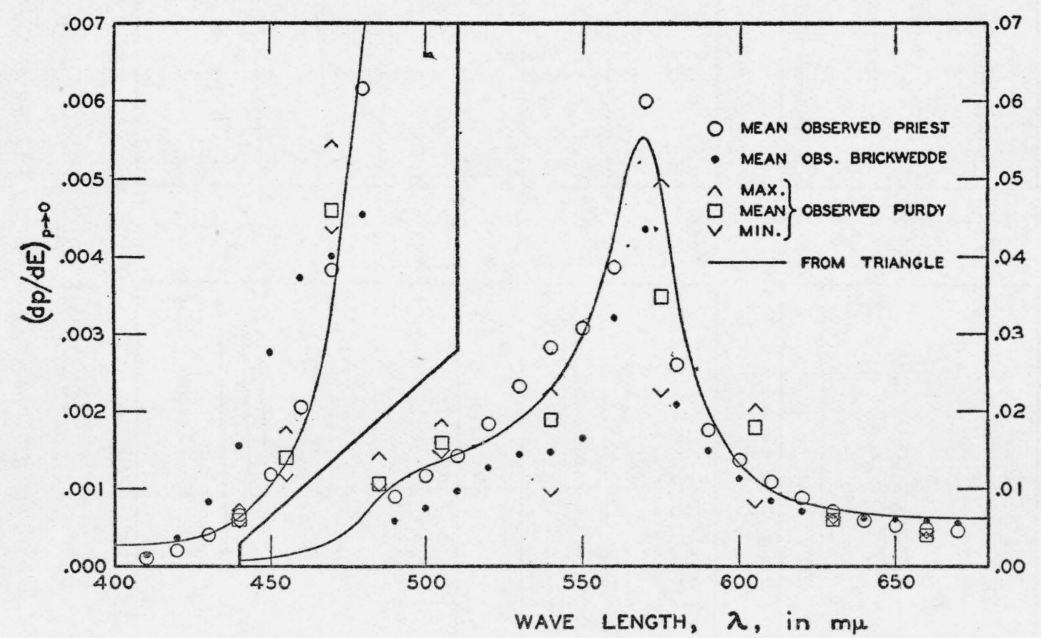

FIGURE 6.-Chromaticity sensibility to purity change near zero purity as a function of dominant wave length.

and by Purdy ${ }^{23}$ results by Martin, Warburton, and Morgan ${ }^{24}$ agree well with these and are not shown. These experimental values have been corrected to refer to the visibility function of the 1931 ICI standard observer on the assumption that the true visibility of the three observers is the experimental mean found by Gibson and Tyndall. ${ }^{25}$ This assumption is known to be closely correct for Priest, who was one of the 52 observers studied by Gibson and Tyndall; and it is probably nearly correct for the other two (Brickwedde, Purdy). The correction was made by multiplying the reported purities by the ratio of standard ICI visibility to experimental visibility $\left(V_{\text {III }} / V_{\text {exp }}\right)$.

${ }^{22}$ I. G. Priest and F. G. Brickwedde, The minimum perceptible colorimetric purity as a function of dominant wave length with sunlight as neutral standard. J. Opt. Soc. Am. and Rev. Sci. Inst. 13, 306 (1926); see also footnote 1 , p. 42.

${ }^{23}$ D. McL. Purdy, On the saturations and chromatic thresholds of the spectral colours. Brit. J. Psych. (Gen. Sec.) 21, pt. 3, 283 (1931).

24 See footnote 17, p. 47.

25 K. S. Gibson and E. P. T. Tyndall, Visibility of radiant energy. BS Sci. Pap. 19, 131 (1923) S475. See first column of their table 3, p. 174. 
This gives the least perceptible colorimetric purity of the field set by the observer as if analyzed photometrically by the standard observer.

In addition to this correction Purdy's values were multiplied by 0.20 to facilitate comparison with the Priest-Brickwedde values. The larger values found by Purdy are attributable to the fact that the size of field used by him (1.5 circular) was less than that used by Priest and Brickwedde ( $4^{\circ}$ square).

The solid curve represents the right-hand member of eq $6 \mathrm{a}$ with Abbot-Priest sunlight taken as the heterogeneous stimulus, that is, for $r_{w}=0.461, g_{w}=0.466, b_{w}=0.073$. This choice was mace bacause Priest and Brickwedde used this heterogeneous stimulıs, and because Purdy used one nearly like this. It will be noted that the agreement shown between the corrected experimental results and those from the triangle is good. The uncorrected purities are hisher than the plotted values between 400 and $440 \mathrm{~m} \mu$ by a factor varying from 3 to 10 . The good agreement obtained with the purities, corrected on the basis of the Gibson-Tyndall experimental visibility suggests that those values may be more representative than the standard values.

\section{(c) NUMBER OF STEPS BETWEEN ZERO AND UNIT PURITY AS A FUNCTION OF WAVE LENGTH}

According to the circle construction the number of just noticeable chromaticity steps between zero and unit purity is proportional to the distance on the triangle between the point representing the hetero-

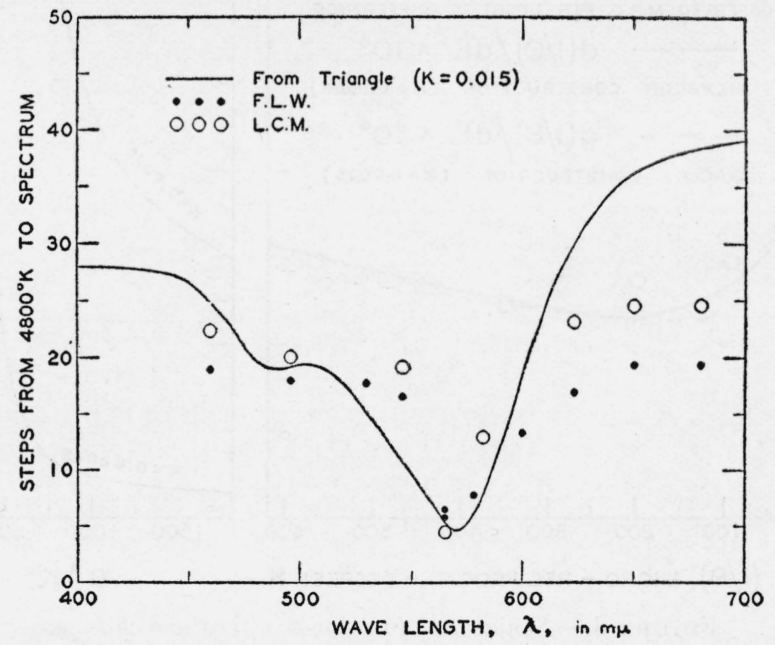

FIgURE 7.-Number of chromaticity steps from a Planckian radiator at $4,800^{\circ} \mathrm{K}$ to the spectrum as a function of dominant wave length.

geneous stimulus and the spectrum locus. From eq 1 and 2 this number may be written:

where

$$
\begin{aligned}
\Delta E & =(1 / K) \sqrt{2\left[(\Delta r)^{2}+(\Delta g)^{2}+(\Delta b)^{2}\right] / 3} \\
\Delta r & =r_{h}-r_{\mathrm{w}}, \Delta g=g_{h}-g_{w}, \Delta b=b_{h}-b_{w} .
\end{aligned}
$$

- Figure 7 shows this number determined experimentally by Warburton and Martin ${ }^{26}$ for a number of dominant wave lengths with the 
heterogeneous stimulus a close color match for a Planckian radiator at $4,800^{\circ} \mathrm{K}$.

The curve on figure 7 gives the right-hand member of eq 7 as a function of dominant wave length for the heterogeneous stimulus used by Warburton and Martin $\left(r_{w}=0.470, g_{w}=0.460, b_{w}=0.070\right)$. As in figure 5 , the constant, $K$, is taken as 0.015 . The agreement is only fair, but it may be worth noting that Martin and Warburton found more steps than indicated by the curve for the brighter part of the spectrum and fewer steps for the extremes of the spectrum. Perhaps more steps would have been found at the extremes if examined at the same field brightness as the middle portion.

\section{SENSIBILITY TO CHANGE IN COLOR TEMPERATURE}

An empirical formula for sensibility to change in color temperature, $\theta$, has already been found and checked ${ }^{27}$ over a considerable range $\left(1,800^{\circ}\right.$ to $\left.11,000^{\circ} \mathrm{K}\right)$ of color temperature:

$$
d(1 / \theta) / d E=\mathrm{a} \text { constant }
$$

This relation has been partially responsible for the proposal that reciprocal temperature be used instead of temperature for color specification of illuminants. ${ }^{28}$

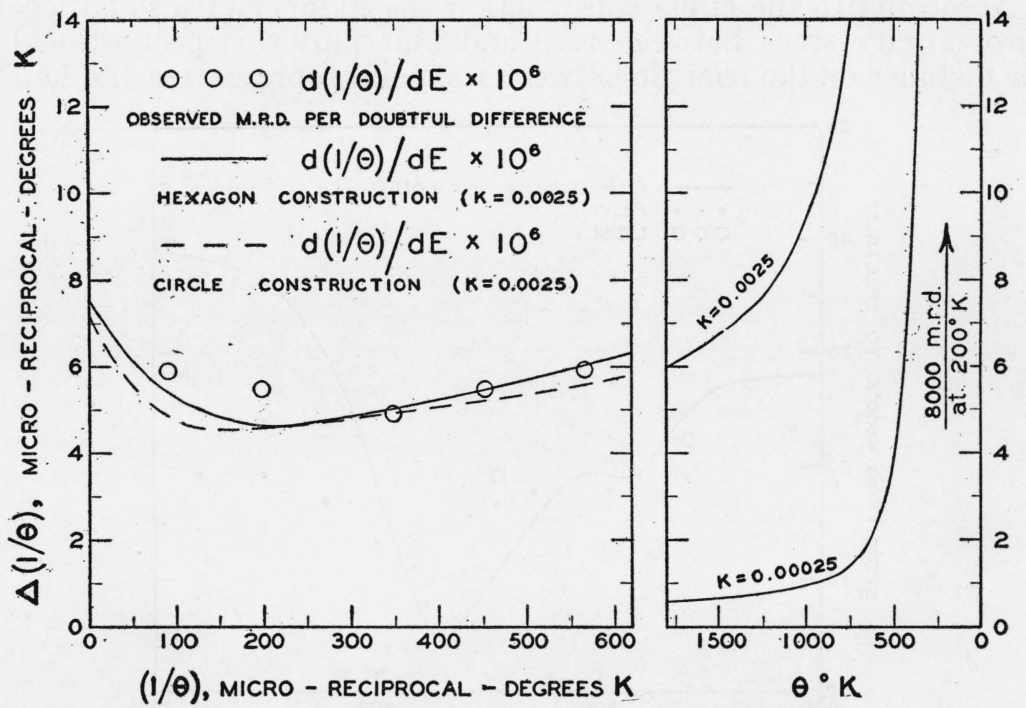

FIgURE 8.-Sensibility to color-temperature change.

From equation 1a it is seen that the hexagon construction yields:

$$
d(1 / \theta) / d E=K d(1 / \theta) / d c
$$

Figure 8 shows (solid curve) the right-hand member of eq 9 as a function of temperature for low temperatures $\left(0\right.$ to $\left.1,800^{\circ} \mathrm{K}\right)$ and as a function of reciprocal temperature for high temperatures $\left(1,600^{\circ} \mathrm{K}\right.$

\footnotetext{
${ }_{27}$ D. B. Judd, Sensibility to color-temperature change as a function of temperature. J. Opt. Soc. Am. 23, 7 (1933).

${ }_{28} \mathrm{I}$. G. Priest, A proposed scale for use in specifying the chromaticity of incandescent illuminants and various phases of daylight. J. Opt. Soc. Am. 23, 41 (1933).
} 
up, or from zero to 625 micro-reciprocal-degrees). Although this curve is far from being horizontal over the entire range, it is nearly horizontal over the range $\left(1,800^{\circ}\right.$ to $11,000^{\circ} \mathrm{K}$ or from about 560 to 90 micro-reciprocal-degrees) to which equation 8 applies.

Figure 8 also shows (circles) the data by means of which equation 8 was verified. It is seen that the hexagon construction is also closely verified by these data. The agreement is close enough to raise the question whether the approximate hexagon construction should not be replaced by the circle construction which, from equations 1 and 2, yields:

$$
\frac{d(1 / \theta)}{d E}=\frac{\sqrt{6} K d(1 / \theta)}{2 \sqrt{(d r)^{2}+(d g)^{2}+(d b)^{2}}}
$$

where $d r, d g$, and $d b$ refer to small differences along the Planckian locus. The right-hand member of equation 10 is represented on figure 8 by the dotted curve. It is seen that about the same degree of agreement exists with the experimental data.

\section{SENSIBILITY TO CHANGE IN LOVIBOND NUMBER}

(a) SENSIBILITY TO CHANGE IN LOVIBOND YELLOW

Analogous to equation 10 the circle construction yields:

$$
\frac{d N^{\prime \prime}}{d E}=\frac{\sqrt{6} K d N^{\prime \prime}}{2 \sqrt{(d r)^{2}+(d g)^{2}+(d b)^{2}}}
$$

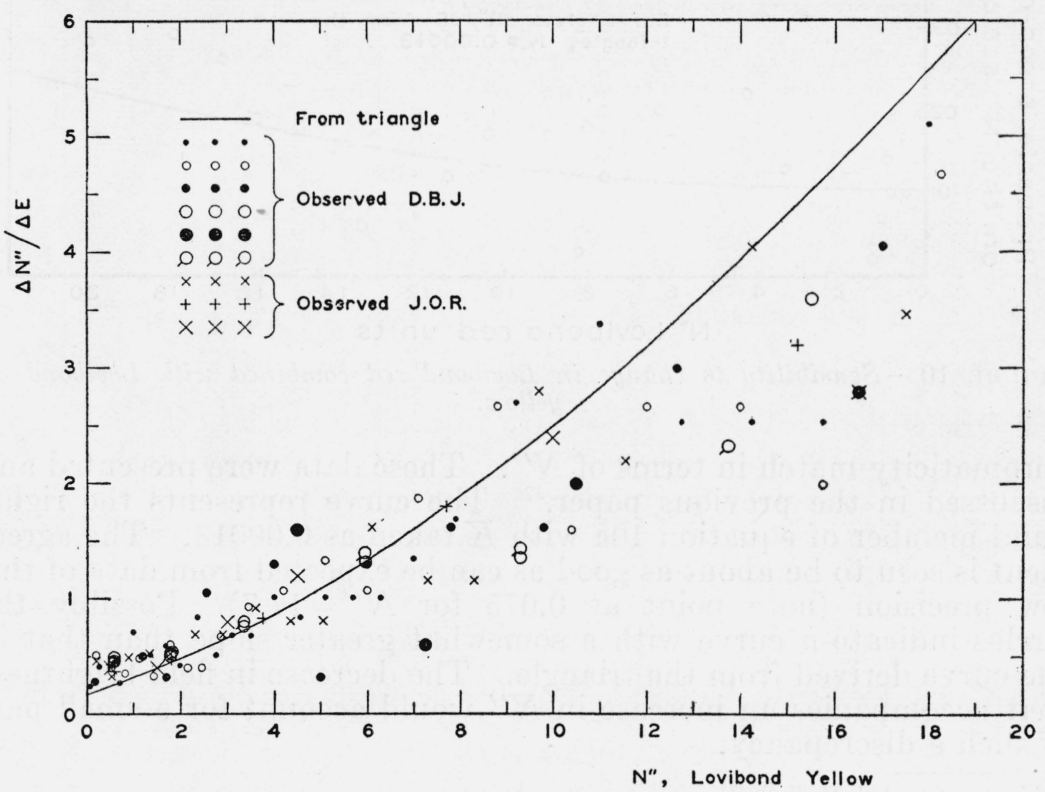

Figure 9.-Sensibility to change in Lovibond yellow.

where $N^{\prime \prime}$ refers to Lovibond-yellow number on the Priest-Gibson scale ${ }^{29}$ and $d r, d g, d b$ refer to differences along the Lovibond-yellow locus.

${ }^{29}$ I. G. Priest and K. S. Gibson, Standardizing the red and yellow Lovibond glasses. J. Opt. Soc. Am. and Rev. Sci. Inst. 16, 116 (1928). 
In figure 9 are shown experimental determinations of this quantity ${ }^{30}$ previously reported as $d p / d E$ on the somewhat inaccurate assumption that the dominant wave length for the Lovibond yellow glasses is constant. The curve represents the right-hand member of equation 10 a with $K$ taken as 0.0045 . It is seen that the agreement is fair.

\section{(b) SENSIBILITY TO CHANGE IN LOVIBOND RED COMBINED WITH 35 YELLOW}

Equation 10a applies to this case also if $N^{\prime \prime}$ is taken to refer to Lovibond-red number on the Priest-Gibson scale ${ }^{31}$ combined with 35 yellow, and if $d r, d g, d b$ refer to differences along the Lovibond $35 Y+N^{\prime \prime} R$ locus.

In figure 10 are shown some rather inaccurate determinations of this quantity by way of the probable error of a single setting for

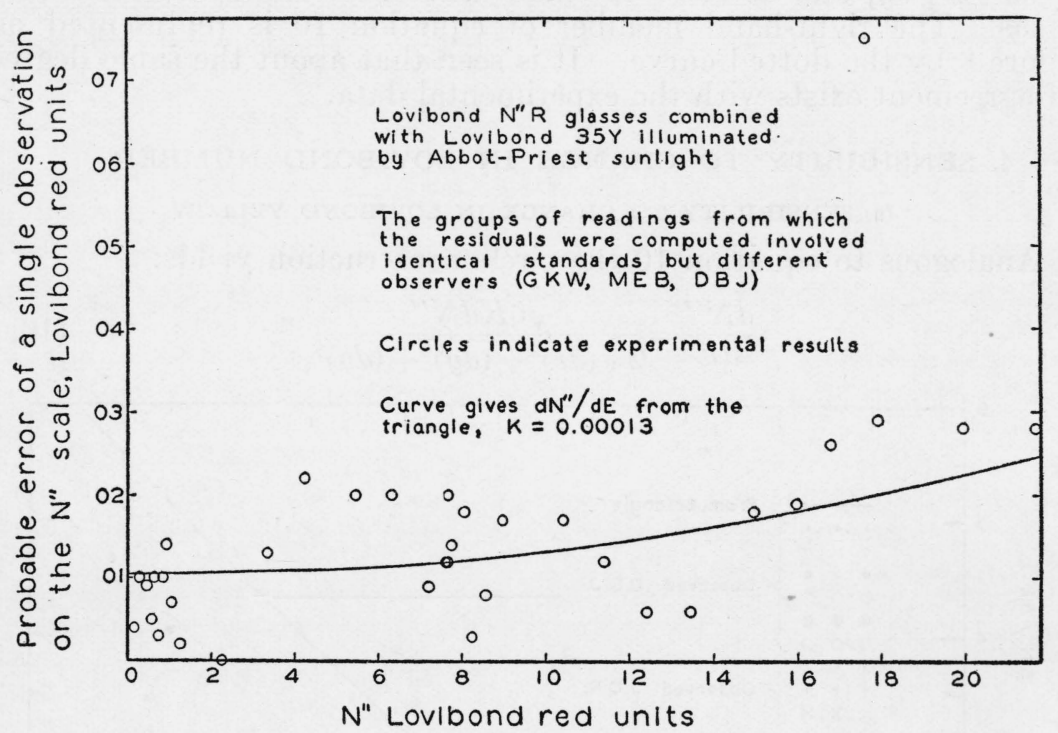

FigURE 10.-Sensibility to change in Lovibond red combined with Lovibond 35 yellow.

chromaticity match in terms of $N^{\prime \prime}$. These data were presented and discussed in the previous paper ${ }^{32}$ The curve represents the righthand member of equation 10a with $K$ taken as 0.00013 . The agreement is seen to be about as good as can be expected from data of this low precision (note point at 0.075 for $N^{\prime \prime}=17.7$ ). Possibly the circles indicate a curve with a somewhat greater slope than that of the curve derived from the triangle. The decrease in field brightness that accompanies an increase in $N^{\prime \prime}$ would account for a small part of such a discrepancy.

\footnotetext{
${ }^{30}$ J. Opt. Soc. Am. 23, 35 (1933).

31 K. S. Gibson and G. W. Haupt, Standardization of Lovibond red glasses in combination with Lovibond 35 yellow. J. Research NBS 13, 433 (1934) RP718.

${ }_{32}$ J. Opt. Soc. Am. 22, 98 (1932).
} 


\section{CONCLUSIONS FROM THE COMPARISONS}

In every case the agreement previously obtained has been equaled or bettered, and in one case it has been notably improved. (See fig.6.) Agreement with data appearing since the previous paper has also been satisfactory. Considering the rather large individual-observer variation it is estimated that the uniform-chromaticity-scale triangle represents about nine-tenths of available data on chromaticity sensibility within their experimental uncertainty.

\section{APPLICATIONS OF THE TRIANGLE}

The data presented indicate that the system chosen yields, as intended, a Maxwell triangle on which to a good approximation the length of a line is proportional to the chromaticity difference between the stimuli represented at its extremes. Although the data examined nearly all referred to small differences it is probable that the approximation is of the same order for large differences. ${ }^{33}$ The degree of approximation, while by no means sufficient to disprove Schrödinger's ${ }^{34}$ theoretical conclusion that such a representation should be made on a spherical surface, is close enough to be of some theoretical interest. Since the coordinate system chosen is only one of an infinity of systems each having the same essential property, it appears possible to fit with certain restrictions the uniform-chromaticity-scale triangle to many of the theories of vision, such as the Hering opponentcolors theory, the Young-Helmholtz three-components formulation, Hecht's ${ }^{35}$ modification of it, or the level theory of G. E. Müller..$^{36}$ In this way the implications of the uniform-scale triangle might find expression in a variety of theoretical terms. Possibly, too, the theoretical formulation which is found to accommodate the uniformscale triangle most conveniently may be thought to have some advantage over the others.

Two practical applications of the triangle may be pointed out. One obvious use is the estimation of the chromaticity difference between any two stimuli from their tristimulus specifications. To accomplish this with maximum accuracy the tristimulus specifications must be transformed by appropriate equations such as equations 3 or 3a. However, the mixture diagram of the standard 1931 ICI coordinate system might be made use of directly to find approximate values of chromaticity difference provided some means were available to take into account the distortion between the two diagrams. A convenient way to do this is to cover the uniform-scale triangle with a number of (say 30) equal circles; then transform by equation 3 these circles to the 1931 ICI mixture diagram where they will appear as ellipses. The expansion or contraction of the various parts of the diagram relative to corresponding parts of the uniform-scale diagram would be indicated by the sizes, eccentricities, and orientations of these ellipses.

33 J. Opt. Soc. Am. 23, 35 (1933).

34 E. Schrödinger, Grundlinien einer Theorie der Farbenmetrik im Tagessehen. Ann. d. Physik [4], 63, 481 (1920); Die Gesichtsempfindungen, Müller-Pouillets Lehrbuch der Physik, 2d ed., 2, 552 (1926).

${ }_{35}$ Selig Hecht, The interrelation of various aspects of color vision. J. Opt. Soc. Am. 21, 615 (1931).

36 G. E. Müller, Ửber die Farbenempfindungen. Leipzig: Barth (1930). 
Perhaps the most important practical application of the uniformscale triangle is its use in finding from any series of colors the one most resembling any neighboring color of the same brilliance. The method, of course, is to draw the shortest line from the locus of the series to the point representing the neighboring color. This is the geometric equivalent of the method of observation on which many plans of color grading are based. The characteristic of these plans is that they pay attention to chromaticity differences along a series of color standards, and in the usual case that no member of the series gives a perfect chromaticity match, the nearest match is set and the residual difference neglected. In this way a problem which, strictly, is two-dimensional finds a one-dimensional solution that is close enough to be of practical use.

Examples of this plan are the color-grading of illuminants according: to the color temperature, ${ }^{37}$ the grading of cottonseed oil according to Lovibond red number combined with Lovibond 35 yellow, ${ }^{38}$ and the grading of lubricating oil according to the standards of the wellknown Union colorimeter. ${ }^{39}$ Many uses of a color comparator (such as the Duboscq) having for comparison a column of liquid of variable height are more or less allied to this plan of color grading; those involving a column producing a relatively large brightness change are little allied, but those involving chiefly changes in chromaticity are good examples of this plan.

In finding nearest color from a series the uniform-scale triangle may be used directly. The locus of the series is plotted together with the point representing the neighboring chromaticity, and the normal to the locus through the point gives the nearest chromaticity of the series. This necessitates transforming the tristimulus specification of the given chromaticity to the uniform-scale triangle each time. It is also possible to carry out the operation once for all by drawing on the uniform-scale triangle a large number of normals to the locus of the series completely covering at sufficiently small intervals the areas of the triangle near the locus. These normals could then be transformed by equation 3 to the standard 1931 ICI coordinate system and they would permit nearest chromaticity to be found from trilinear coordinates in the standard system without the necessity for transformation each time to the uniform-scale triangle. It is planned to do this for the Planckian locus to facilitate finding nearest color temperature. Preliminary comparison of nearest color temperatures found by the uniform-scale triangle indicates good agreement with those found by Davis' empirical method. ${ }^{40}$

\footnotetext{
37 I. G. Priest, The complete scale of color temperature * * *. Phys. Rev. [2], 20, 93 (1922); The colorim etry and photometry of daylight and incandescent illuminants * * *, J. Opt. Soc. Am. and Rev. Sci. Inst., \%, 1175 (1923).

${ }_{38}$ Report of Color Committee of the American Oil Chemists' Society, 1932-1933. Oil and Soap, 10,114 (1933).

39 In this instrument no provision at all is made for equalizing the brightnesses of the two fields; hence, the problem, strictly a tridimensional one, is reduced to a single specification by neglecting both small chromaticity and small brilliance differences.

${ }_{40}$ R. Davis, A correlated color temperature for illuminants. BS J. Research, 7, 659 (1931) RP 365.
} 


\section{SUMMARY}

The uniform-chromaticity-scale triangle is shown to be in good agreement with a large proportion of published data on chromaticity sensibility. The scope, reliability, and consistency of these data are such that it is planned to use the triangle for estimation of chromaticity differences and for the determination of nearest chromaticity from a series for any neighboring chromaticity.

\section{APPENDIX}

If it be desired to avoid the use of triangular coordinate plots, the trilinear coordinates, $r, g, b$, may be plotted in rectangular coordinates by the transformation:

$$
\begin{aligned}
& x=(2 b+g) / \sqrt{3} \\
& y=g
\end{aligned}
$$

where $x$ and $y$ are abscissa and ordinate, respectively, of the usual rectangular coordinates. ${ }^{41}$ These transformations place the equilateral triangle (see fig. 1) in the first quadrant of the $(x, y)$-plot, with the $G$-point $(r=0, g=1, b=0)$ uppermost and the $R$-point $(r=1, g=b=0)$ at the origin $(x=y=0)$.

In rectangular coordinates eq 2 may be written in the familiar form:

$$
D=\sqrt{(\Delta x)^{2}+(\Delta y)^{2}}
$$

and eq 2a becomes:

$$
D=\left\{\begin{array}{l}
\Delta x \sqrt{(\Delta y / \Delta x)^{2}+1}, \text { or } \\
\Delta y \sqrt{(\Delta x / \Delta y)^{2}+1}
\end{array}\right.
$$

Washington, November 9, 1934.

\footnotetext{
${ }^{41}$ Note distinction from $\bar{x}$ and $\bar{y}$ of eq 3 .
} 